\title{
Bioreductive Agent
}

National Cancer Institute

\section{Source}

National Cancer Institute. Bioreductive Agent. NCI Thesaurus. Code C2077.

Antitumor agents that are activated by biological reduction and have selective efficacy against hypoxic solid tumors. ( $\mathrm{NCl})$ 